\section{Scientists try new strategy to eradicate dengue fever}

Georgina Kenyon, Sydney

A new programme, sponsored by the governments of the United Kingdom and Australia, has been successful in reducing the risk of dengue fever in parts of Vietnam. The Australian Foundation for the Peoples of Asia and the Pacific, an aid organisation, recently completed a three year programme using the mesocyclops crustacean, which is about $1 \mathrm{~mm}$ long and devours the larvae of the mosquitos that carry dengue fever.

Researchers say that the results look promising. The programme appears to have rid the northern Vietnamese province of Phan Boi of the larvae, and there was a $75 \%$ success rate in other provinces.

The non-governmental Queensland Institute of Medical Research and the Vietnam National Institute of Hygiene and Epidemiology were the organisations involved in $\mathrm{CO}-$ ordinating drops of the organism into mosquito breeding areas such as wells, water tanks, and household water containers.

A community education and clean up programme was also put in place to educate residents about the importance of discarding unused buckets and other containers that could hold stagnant water and which could become potential breeding grounds for disease.

Professor Brian Kay, from the Queensland institute's malaria and arbovirus unit, said that dengue is usually transmitted by the Aedes aegypti mosquito, and that more than 170000 Vietnamese were infected each year. He said that prevention of the disease is important because existing treatments are inadequate.

Current procedures to con-

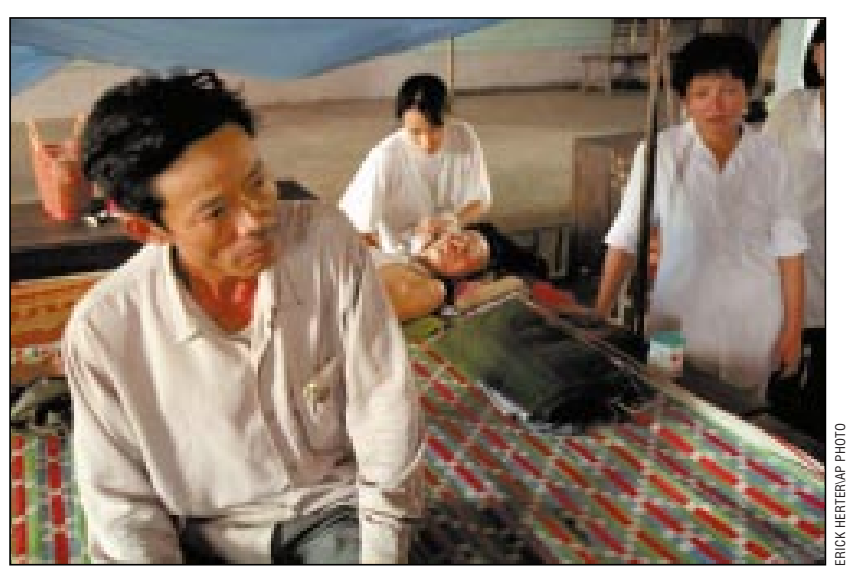

More than 170000 Vietnamese are infected with dengue each year

trol the disease usually include interrupting the breeding cycles of the mosquitos as well as the use of insecticides. Both are inadequate in the long term. There is no vaccine.

Global warming is also increasing the necessity for prevention, according to World Wildlife Fund spokesman Dr Paul Epstein, from Harvard Medical School. He warned in a November 1998 report on climate change, which was submitted to the United Nations, that the warming of the earth will cause a rise in infectious diseases including dengue, malaria, cholera, yellow fever, and encephalitis.

Dengue is present in tropical and subtropical areas, including south east Asia and northern parts of South America, particularly Brazil. It has also been detected in north Australia and Argentina.

\section{New guidelines for mild hypertension published}

Paul Dinsdale, London

Revised guidelines on treating patients with mild hypertension have been drawn up by the World Health Organisation and the International Society of Hypertension.

The main recommendations of the guidelines, which update those issued in 1993, include the use of stratified risks to guide the management of patients with hypertension; the introduction of lower blood pressure targets (below 130/85mm Hg); the use of a choice of drugs from among six major classes to begin treatment depending on the characteristics of the patient; and the encouragement of clinicians to use a combination of drugs to achieve blood pressure targets.

The guidelines concentrate on the management of patients with "mild" hypertension because clinicians and policymakers often disagree about its treatment, according to the two organisations.

One important development is the addition of the newest class of drugs, angiotensin II antagonists, to the range of drugs recommended for treatment of the condition. Since their launch, several studies have reported that the drugs are effective and are well tolerated.

"The main philosophy of the new guidelines is concentrating on blood pressure targets rather than particular drugs," said Professor Peter Sleight, honorary consultant at the John Radcliffe Hospital in Oxford, president of the World Hypertension League, and a member of the WHO committee that drew up the guidelines.

"The thinking is that to reduce blood pressure we need to use at least two drugs in combination, possibly three. Clinicians have to use all drugs intelligently rather than sticking to one particular category."

The guidelines are published in the Journal of Hypertension (1999;17:151-83).

\section{Primary care trusts will have wide powers}

Linda Beecham, $B M J$

Primary care trusts, which will be set up in England under the Health Bill now going through parliament, will have wide ranging powers.

Whereas primary care groups are committees of health authorities, primary care trusts will be free standing, statutory bodies, responsible for the healthcare budgets of the majority of hospital and community health services. Typically, a trust will have a budget of at least $£ 60 \mathrm{~m}(\$ 96 \mathrm{~m})$.

In a letter to the chairpeople and chief executives of health authorities, NHS trusts, and primary care groups on the governance of the primary care trusts the health minister John Denham says, "No other body has the same range of flexibilities and opportunity to improve services." The new primary care trusts will be able to enter into service agreements with other parts of the NHS and will have a major role in developing primary care.

A trust executive committee will be responsible for the day to day running of the primary care trusts and will have a majority of professional members. The government wants the new trusts to be responsive to people's health needs and wishes, and a trust board, which will have overall responsibility for the performance of the trust, will have a majority of lay members. Lay members and chairpeople will be appointed by the health secretary.

The letter says that primary care trusts will be expected to work in partnership with NHS trusts and hospital doctors, particularly on the commissioning of services.

The chairman of the BMA's General Practitioners Committee, Dr John Chisholm, said that the letter left many questions unanswered. "How much say will doctors, nurses, and patients have in the decision to move to trust status? How will the proposals deliver the government's promise that GPs and nurses will remain in the driving seat?" 